\title{
The Correlation of Religious Orientation with Depression Among Critical Care and Emergency Room Nurses
}

\author{
Marzieh Mogharab, ${ }^{1}$ Kobra Nateghi, ${ }^{2,}$ Ahmad Shamaie-Zavareh, ${ }^{3}$ and Gholamreza Sharifzadeh ${ }^{4}$ \\ ${ }^{1}$ Department of Nursing, and Midwifery, Birjand University of Medical Sciences, Birjand, Iran \\ ${ }^{2}$ Department of Nursing, Faculty of Nursing and Midwifery, Birjand University of Medical Sciences, Birjand, Iran \\ ${ }^{3}$ Health Center, Isfahan University of Medical Sciences, Isfahan, Iran \\ ${ }^{4}$ Social Determinants of Health Research Center, Birjand University of Medical Sciences, Birjand, Iran \\ "Corresponding author: Kobra Nateghi, Msc of Nursing Education, Faculty of Nursing and Midwifery, Birjand University of Medical Sciences, Birjand, Iran. Tel: +98-5632440550, \\ Fax: +98-5632440550, E-mail: kobra_nategh@yahoo.com
}

Received 2015 October 17; Revised 2016 June 03; Accepted 2016 July 10.

\begin{abstract}
Background: Nurses who work in special care units are at great risk of developing mental health problems. The present study was performed to examine the correlation of religious orientation with depression among critical care and emergency room nurses. Methods: This descriptive, analytical study was performed in 2015 on 109 nurses working in critical care units and emergency rooms of Valiasr and Imam Reza hospitals, Birjand, Iran. The nurses were recruited through census sampling. Data were collected using Beck Depression Inventory and Allport's Religious Orientation Scale. For statistical analysis, independent sample t test, one-way analysis of variance, Tukey's post hoc test, and Pearson's correlation coefficient test were performed, using SPSS v. 16 at a significance level of less than 0.05 .

Results: The nurses' mean scores of extrinsic and intrinsic religious orientations were $31.56 \pm 7.39$ and $29.73 \pm 4.26$, respectively. There was no significant correlation between the general religious orientation and depression $(r, 0.02 ; \mathrm{P}=0.83)$. However, depression was correlated negatively with intrinsic religious orientation $(r,-0.37 ; \mathrm{P}=0.001)$ and positively with extrinsic religious orienta$\operatorname{tion}(\mathrm{r}, 0.24 ; \mathrm{P}=0.01)$. Overall, $27.5 \%$ and $0.9 \%$ of nurses had mild and moderate depression, respectively. Depression was significantly correlated with the nurses' gender and income $(\mathrm{P}=0.01)$.

Conclusions: Given the significant correlation of depression with intrinsic and extrinsic religious orientations, it seems that health authorities need to develop plans for purifying and strengthening nurses' religious beliefs.
\end{abstract}

Keywords: Religious Orientation, Allport's Religious Orientation Scale, Beck Depression Inventory, Critical Care Nurse, Emergency Room Nurse

\section{Background}

Depression has been a major mental health problem for centuries. It is among the most prevalent debilitating conditions in different countries. Currently, about 330 million people suffer from depression around the world, and 800000 depression-related suicides are annually committed (1). Almost $15 \%$ of the general population experience a period of major depression during their lives (2). The prevalence of depression in Iran has been reported to widely range from $4.2 \%$ to $37 \%$ (3). Overall, the prevalence of depression and some other physical health problems is progressively increasing worldwide due to social, economical, and environmental changes.

Depression and its associated complications can negatively affect the work environment, cause interpersonal tensions, disrupt the process of work, and affect employee work attendance, efficiency, and precision. People with depression are almost 27 times more likely to feel unable to perform their professional duties, compared to healthy people. In fact, depression accounts for $30 \%$ of reduced productivity and absence from work and 70\% of workrelated errors and disabilities (1). Also, depression is not specific to certain populations or groups; yet, some people are more susceptible due to their unique conditions (2).

Workplace continuously affects individuals. Also, job characteristics and one's personal and mental features are continuously in a mutual and dynamic relationship with each other (4). Nurses are under great psychological pressure, and consequently, depression, anxiety, and fatigue are highly prevalent among them (5). At workplace, nurses experience different stressors and pressures, which can affect their mood and cause depression. A study in Tehran, Iran, showed that $73.1 \%, 21.5 \%$, and $5.4 \%$ of nurses had mild, moderate, and severe depression, respectively (4). Nelson and Simmons (2001), citing the U.S. National Institute for Occupational Safety, showed that among 130 professions, nursing was the 27th profession with the highest prevalence of mental and occupational problems (6).

Compared with other groups of nurses, critical care nurses experience higher levels of stress due to the unique 
conditions of their clients and their work conditions. There is a wide range of stressors in critical care units, which include, but are not limited to, heavy workload, great responsibility of patient care, need for quick reactions in emergency situations, and unique characteristics of critically ill patients (including their severe health problems and inability to communicate) (7).

Moreover, critical care nurses are usually under great strain due to different factors, such as frequent contact with critically ill patients, patients' variable health conditions, working with incompetent colleagues, low nursepatient ratio (or shortage of competent staff), medical residents' lack of knowledge or expertise, rotational shifts, poor nurse-manager communication, and shortage of diagnostic and therapeutic equipments. Such strains cause job burnout, frustration, fatigue, anger, isolation, and ineffective decision-making among nurses.

Critical care and emergency room nurses are responsible for problem identification, situational and environmental assessment, and implementation of appropriate interventions (8). Emergency room nurses also experience higher levels of stress, compared with other nurses due to their exposure to frequent stressors and tensions (9).

The negative effects of depression and the associated complications can be reduced through employing different strategies including religiosity. In this regard, Rezapour-Mirsaleh et al. (2011), quoting Rash, the father of American psychology, stated that "religion is as important for the human soul as air for respiration" (10). In fact, religious beliefs can promote one's personal integrity and give meaning to life.

Mentally ill patients are reported to lack the stability and integrity arising from religious beliefs (11). Therefore, as a cultural factor and an inner need, religious beliefs can affect one's mood and predict some mood-related characteristics. Intrinsic and extrinsic religious orientations give people direction, support, and hope; thereby, they can play a significant role in understanding and coping with stressful life events. Religiosity has been found to exert its coping-related effects through 3 main mechanisms: giving meaning to life, helping people have a sense of control when facing different situations, and creating a sense of self-confidence (10).

Religiosity is a source of meaning and hope, which can alleviate mental and physical health problems (11). Stronger faith in God is associated with stronger immunity to psychological and mental health problems. Ghanbari et al. (2011) also noted that religiosity is a firm basis for coping with problems, difficulties, and shortcomings in life (12). Studies have shown that the spiritual aspects of religiosity or intrinsic religious orientation can decrease the symptoms of depression (12).
Moreover, religiosity, extrinsic religious orientation, and religion rituals (eg, saying prayers and reading holy books) can protect people against mental disorders $(13,14)$. Moreover, religious beliefs seem to decrease the symptoms of depression among students, as well as patients with schizophrenia and acquired immunodeficiency syndrome (AIDS) $(10,12,15)$. However, according to 2 previous studies, religiosity has no significant effects on general health (16) and depression (17).

Considering the conflicting findings of previous studies on the relationship between depression and religious orientation and the importance of these factors in the health of nurses and their patients, in the present study, we aimed to examine the correlation of religious orientation with depression among critical care and emergency room nurses.

\section{Methods}

This descriptive, analytical study was performed in 2015 on 109 nurses working in critical care units and emergency rooms of Valiasr and Imam Reza hospitals, Birjand, Iran. The nurses were recruited through census sampling. The inclusion criteria were work experience of at least 1 year in critical care units or emergency rooms, no use of psychiatric medications, and minimum of 15 six-hour work shifts per month.

A 3-part instrument was used to collect the data. The first part comprised of 9 items on nurses' demographic characteristics, such as gender, marital status, hospital ward, and income level (categorized as excellent, good, moderate, and low). The second part was the 21-item Beck Depression Inventory (BDI), which measures the severity of depression-related emotional, cognitive, and physical symptoms.

In $\mathrm{BDI}$, there are 4 possible responses for each item, scored from 0 (absent) to 3 (severe). Therefore, the total BDI score ranges from 0 to 63 (18). Besides reporting the mean BDI score, we categorized the total BDI score into 4 categories: 0 -16, no depression; 17-32, mild depression; 33 - 47, moderate depression; and $46-63$, severe depression. BDI has been used in different studies and has been reported to have acceptable reliability $(4,18)$.

The third part of the instrument included Allport's religious orientation scale (ROS). ROS was developed in 1950 by Allport and Ross for measuring intrinsic and extrinsic religious orientations (19). It contains 12 items on extrinsic religious orientation and 9 items on intrinsic religious orientation (21 items in total). Mokhtari et al. (2001) crossculturally adapted ROS for the cultural and religious context of Iran and reported a Cronbach's alpha of 0.71 for the Farsi version of the scale (20). 
The items of the extrinsic religious orientation domain were scored as follows: completely disagree, 1 ; almost disagree, 2; almost agree, 4; and completely agree, 5 . On the other hand, all items of the domain of intrinsic religious orientation were reversely scored. The questionnaires were administered to 120 critical care and emergency room nurses. Finally, 109 nurses completed the questionnaires; eleven nurses were excluded due to incomplete questionnaires.

SPSS v. 16 was used to describe the data through measuring descriptive statistics (eg, mean, standard deviation, and raw and relative frequencies). To analyze the data, independent sample t test, one-way analysis of variance (ANOVA), Tukey's post hoc test, and Pearson's correlation coefficient test were performed. All statistical analyses were performed at a significance level of $<0.05$. The ethics committee of Birjand University of Medical Sciences, Birjand, Iran, approved the study (approval code IR.BUMS.1394.386)

\section{Results}

This study was performed on 109 nurses working in critical care units and emergency rooms of Valiasr and Imam Reza hospitals, Birjand, Iran. The majority of nurses were female (82.2\%) and married (80.7\%), held a bachelor's degree in nursing (93.6\%), worked in critical care units (58.7\%), and were affiliated to Valiasr hospital (75.2\%). Moreover, 33\% of the nurses had secured conditional permanent employment, while $28.4 \%$ had nonconditional permanent employment (Table 1).

The nurses' mean scores of depression, extrinsic religious orientation, and intrinsic religious orientation were $10.83 \pm 8.36,31.56 \pm 7.39$, and $29.73 \pm 4.26$, respectively. Around $71.6 \%$ of nurses had no depression, while $27.5 \%$ and $0.9 \%$ had mild and moderate depression, respectively. The results revealed that depression was correlated negatively with intrinsic religious orientation $(\mathrm{r},-0.37 ; \mathrm{P}=0.001)$ and positively with extrinsic religious orientation $(\mathrm{r}, 0.24 ; \mathrm{P}=$ 0.01).

Further analysis of the data indicated that depression was significantly more prevalent among female nurses ( $P$ $=0.03$ ). Moreover, nurses with conditional permanent employment and those on postgraduation mandatory service obtained higher extrinsic religious orientation scores, compared to those who had nonconditional permanent employment or those who worked under contract $(\mathrm{P}=$ 0.02; Table 2). Furthermore, there was a negative significant correlation between depression and income (r, -0.24; $\mathrm{P}=0.02$ ).
Table 1. The Frequency Distribution of Participants' Demographic Characteristics

\begin{tabular}{|c|c|}
\hline Variables & $\mathbf{N}(\%)$ \\
\hline \multicolumn{2}{|l|}{ Gender } \\
\hline Female & $90(82.6)$ \\
\hline Male & $19(17.4)$ \\
\hline \multicolumn{2}{|l|}{ Marital status } \\
\hline Single & $21(19.3)$ \\
\hline Married & $88(80.7)$ \\
\hline \multicolumn{2}{|l|}{ Affiliating hospital } \\
\hline Valiasr & $82(75.2)$ \\
\hline Imam Reza & $27(24.8)$ \\
\hline \multicolumn{2}{|l|}{ Extra work } \\
\hline Yes & $102(93.6)$ \\
\hline No & $7(6.4)$ \\
\hline \multicolumn{2}{|l|}{ Hospital ward } \\
\hline Emergency room & $45(41.3)$ \\
\hline Critical care unit & $64(58.7)$ \\
\hline \multicolumn{2}{|l|}{ Number of children } \\
\hline No children & $60(55)$ \\
\hline One child & $25(22.9)$ \\
\hline Two or more & $24(22)$ \\
\hline \multicolumn{2}{|l|}{ Employment status } \\
\hline Contract & $20(18.3)$ \\
\hline Permanent & $31(28.4)$ \\
\hline Conditional permanent & $36(33)$ \\
\hline Postgraduation service & $22(20.2)$ \\
\hline \multicolumn{2}{|l|}{ Organizational position } \\
\hline Head nurse & $2(1.8)$ \\
\hline Nurse & $102(93.6)$ \\
\hline Auxiliary nurse & $5(4.6)$ \\
\hline
\end{tabular}

\section{Discussion}

Based on the results of the present study, the prevalence of mild depression among critical care and emergency room nurses was 27.5\%. Similarly, the World Health Organization reported that the prevalence of depression is $15 \%-20 \%$ and $15 \%-30 \%$ in the general population and among nurses, respectively (6). In previous studies, the prevalence of depression among military nurses, employees of Zanjan University of Medical Sciences, (Zanjan, Iran), and first-year students of Birjand University of Medical Sciences (Birjand, Iran) was $24.9 \%, 40 \%$, and $12.1 \%$, respectively $(1,3,4)$. 
Table 2. Comparison of Nurses' Depression and Intrinsic and Extrinsic Religious Orientation Scores Based on Demographic Characteristics

\begin{tabular}{|c|c|c|c|}
\hline Variables & $\begin{array}{c}\text { Intrinsic Religious Orientation, Mean } \pm \\
\text { SD }\end{array}$ & $\begin{array}{c}\text { Extrinsic Religious Orientation, Mean } \\
\pm \text { SD }\end{array}$ & Depression, Mean \pm SD \\
\hline \multicolumn{4}{|l|}{ Gender } \\
\hline Male & $31.58 \pm 8.73$ & $29.16 \pm 3.71$ & $7.05 \pm 7.44$ \\
\hline Female & $31.55 \pm 7.14$ & $29.85 \pm 4.37$ & $11.6 \pm 8.36$ \\
\hline P value (independent sample $t$ test) & $P=0.99$ & $P=0.52$ & $P=0.03^{*}$ \\
\hline \multicolumn{4}{|l|}{ Hospital } \\
\hline Valiasr & $31.12 \pm 7$ & $29.62 \pm 4.35$ & $11.41 \pm 8.56$ \\
\hline Imam Reza & $32.89 \pm 8.47$ & $30.08 \pm 4.02$ & $9.04 \pm 7.6$ \\
\hline P value (independent sample t test) & $\mathrm{P}=0.28$ & $P=0.63$ & $\mathrm{P}=0.2$ \\
\hline \multicolumn{4}{|l|}{ Hospital ward } \\
\hline Emergency department & $31.73 \pm 7.98$ & $30.31 \pm 4.29$ & $9.91 \pm 8.12$ \\
\hline P value (independent sample t test) & $\mathrm{P}=0.84$ & $\mathrm{P}=0.24$ & $\mathrm{P}=0.34$ \\
\hline \multicolumn{4}{|l|}{ Employment status } \\
\hline Contract & $29.05 \pm 4.43$ & $35.5 \pm 7.32$ & $11.3 \pm 10.38$ \\
\hline Permanent & $29.03 \pm 6$ & $30.71 \pm 3.8$ & $9.74 \pm 9.11$ \\
\hline Conditional permanent & $31.89 \pm 7.88$ & $30.28 \pm 4.63$ & $11.03 \pm 7.8$ \\
\hline Postgraduation service & $31 \pm 7.28$ & $28.09 \pm 3.73$ & $11.59 \pm 6.28$ \\
\hline P value (one-way ANOVA) & $\mathrm{P}=0.02^{* \mathrm{a}}$ & $\mathrm{P}=0.11$ & $\mathrm{P}=0.85$ \\
\hline
\end{tabular}

${ }^{\mathrm{a}}$ The extrinsic religious orientation scores of nurses with conditional permanent employment and those on mandatory postgraduation service were significantly greater than nurses with nonconditional permanent employment or those who worked on contract.

Moreover, the prevalence of mild, moderate, and severe depression among 130 nurses working in Namazi Hospital of Shiraz, Iran, was reported to be $42.4 \%, 13.8 \%$, and $2.6 \%$, respectively (21). The main reasons for depression among nurses and medical staff were stress, tension, distress, witnessing patients' death, poor psychological preparation for managing patients' emotional problems, heavy workload, unclear clinical guidelines, treating aggressive patients, and work pressure $(6,21)$.

Mokhtari et al. (2001) noted that the mentioned factors could cause psychological tension. Moreover, they reported that untreated work-related cumulative psychological tension might finally lead to depression (20). The contradiction between the present findings and the results of some previous studies may be due to differences in the context, setting, data collection instruments, and sample size of these studies. Moreover, sampling from critical care units and emergency rooms might have produced different findings in the present study.

The present findings also revealed a significant negative correlation between depression and intrinsic religious orientation; accordingly, nurses with firmer religious be- liefs had milder depression. The results of a comprehensive study in the Netherlands also showed that strong faith and religiosity were among the main 3 components of life among hospitalized patients. Moreover, only 38\% of patients, who were deeply religious, were at risk for depression. Also, depressed patients who valued religious beliefs could recover from depression faster (22).

In line with our findings, Bayani et al. (2008) and Amrai et al. (2011) reported a significant negative correlation between depression and religious orientation among university students $(2,23)$. Most previous studies have shown that religious beliefs could alleviate depression among different populations, including students and patients with schizophrenia and AIDS $(10,12,15)$. Similarly, Smith et al. (2003) reported a moderate correlation between depression and religious orientation (17).

In contrast, Drayl et al. (2003) reported that religiosity had no significant effect on mental health (16). Such contradiction may be due to differences in the context, religion, and measurement tools in these studies. For instance, Drayl et al. (2003) used the Francis scale of attitude towards christianity (FSAC), which mainly deals with per- 
sonal religious rituals rather than all aspects of religiosity.

Allport noted that differentiation of intrinsic and extrinsic religiosity helps make a distinction between those who consider religiosity as an aim and those who use it as an instrument. The present findings also showed that nurses who considered religiosity as a goal had lower levels of depression, compared with those who used it to receive support. Considering their instrumental approach to religiosity, people with an extrinsic religious orientation have shakable faith, and therefore, they are not as mature and peaceful as people with an intrinsic religious orientation.

It is worth noting that people with an intrinsic religious orientation believe that everything happens at God's will, and as a result, no one except God can cause them distress. Moreover, people with firm religious beliefs usually use problem-focused coping mechanisms, and therefore, they show more effective coping in different situations (20).

The findings also revealed that the mean score of extrinsic religious orientation was greater than the mean score of intrinsic religious orientation (20). People with an intrinsic religious orientation have coherent and wellorganized religious beliefs, consider religious values as an aim, and pay little attention to nonreligious values and needs. Contrarily, people with an extrinsic religious orientation use religiosity as a means to fulfill their needs, reach personal and social balance and security, and attract others' attention to themselves. In other words, they use religiosity as a means for achieving other objectives (24).

Another finding of the present study was that nurses who worked permanent and post-graduation service obtained higher extrinsic religious orientation scores probably due to their younger ages and greater time and desire for doing group works and participating in social and religious activities. On the other hand, the findings showed a significant difference between male and female nurses with respect to the depression scores. Most previous studies have also reported the higher prevalence of depression among female medical students and military nurses due to their greater susceptibility to depression $(4,24)$. These findings contradict the findings reported in 2 previous studies on students and emergency room staff in Birjand, Iran, and New York, USA, respectively $(3,25)$.

Another finding of the present study was the negative correlation of depression with income; in fact, nurses with higher income had lower levels of depression. Similarly, Dalmida et al. (2012) reported higher levels of tranquility among Master's degree students who had a greater family income (26).

\subsection{Conclusion}

Considering the $27.5 \%$ prevalence of mild depression among nurses and the positive correlation of depression with extrinsic religious orientation, it seems that nurses paid greater attention to the superficial aspects of religiosity. On the other hand, the negative correlation of depression with intrinsic religious orientation indicates nurses' little attention to the superficial aspects of religiosity. Therefore, specialized counseling services by religious experts can help improve nurses' religiosity and reduce their depression.

\section{References}

1. Fallah R, Farhadi S, Amini K, Mohajeri M. Prevalence of depression in personnel of zanjan university of medical sciences (in Persian). JZanjanUniv Med Sci. 2011;19(75):107-14.

2. Bayani AA, Goudarzi H, Bayani A, Kouchaki AM. The relationship between the religious orientation and anxiety and depression of university students (in Persian). Quarterly J Fundament Ment Health. 2008;10(3):209-14.

3. Hasanzadeh Taheri M, Mogharab M, Akhbari SH, Raeisoon MR, HasanzadehTaheri E. Prevalence of depression among new registered students in Birjand University of Medical Sciences in the academic year 2009-2010 (in Persian). J BirjandUniv Med Sci. 2011;18(2):109-16.

4. AsadZandi M, Sayari R, Ebadi A, Sanainasab H. Abundance of depression, anxiety and stress in militant Nurses (in Persian). JMil Med. 2011;13(2):103-8.

5. Angermeyer MC, Bull N, Bernert S, Dietrich S, Kopf A. Burnout of caregivers: a comparison between partners of psychiatric patients and nurses. Arch Psychiatr Nurs. 2006;20(4):158-65. doi: 10.1016/j.apnu.2005.12.004. [PubMed: 16846776].

6. Simmons BL, Nelson DL. Eustress at work: the relationship between hope and health in hospital nurses. Health Care Manage Rev. 2001;26(4):7-18. [PubMed: 11721311].

7. Rahmani F, Behshid M, Zamanzadeh V, Rahmani F. Relationship between general health, occupational stress and burnout in critical care nurses of Tabriz teaching hospitals (in Persian). Iran JNurs. 2010;23(66):54-63.

8. RafatiRahimzadeh M. A comparison of individual problems of nurses in emergency and cardiac care unit (in Persian). J BabolUniv Med Sci. 2002;4(3):51-7.

9. Saberi HR, Moravveji SAR, Ghoraishi F, Heidari Z. Post-traumatic stress disorder in Kashan and Arak emergency medicine departments' staffs during 2009 (in Persian). Feyz. 2009;12(5):1-6.

10. RezaporMirsaleh Y, Khabbaz M, Safi MH, Abdi K, Yavari M, Behjati $Z$. The relationship of religiosity, personality dimensions and selfefficacy with coping style of nurses practitioner students (in Persian). Iran JNursRes. 2011;6(22):53-64.

11. Mohr S, Brandt PY, Borras L, Gillieron C, Huguelet P. Toward an integration of spirituality and religiousness into the psychosocial dimension of schizophrenia. Am J Psychiatry. 2006;163(11):1952-9. doi: 10.1176/ajp.2006.163.11.1952. [PubMed: 17074947].

12. Ghanbari V, Rahmati M, Beighmohammadi G, Khaledipaveh B. Effect's of group reading the quran on depression of schizophrenic patients (in Persian). Nurs Midwifery J. 2011;6(22):19-25.

13. Peres JF, Simao MJ, Nasello AG. Spirituality, religiousness and psychotherapy. Rev Psiq Clín. 2007;34(Supl1):58-66.

14. Moss Q, Fleck DE, Strakowski SM. The influence of religious affiliation on time to first treatment and hospitalization. Schizophr Res. 2006;84(2-3):421-6. doi: 10.1016/j.schres.2006.02.002. [PubMed: $16546355]$. 
15. Lee M, Nezu AM. Religious coping, depression, and quality of life in people living with HIV/AIDS. Drexel University; 2012.

16. O'Connor DB, Cobb J, O'Connor RC. Religiosity, stress and psychological distress: No evidence for an association among undergraduate students. PersIndivid Dif. 2003;34(2):211-7.

17. Smith TB, McCullough ME, Poll J. Religiousness and depression: Evidence for a main effect and the moderating influence of stressful life events. Psychol Bull. 2003;129(4):614-36.

18. Beck AT, Steer RA, Garbin MG. Psychometric properties of the beck depression inventory: twenty -five years of evaluation. ClinPsychol Rev. 1988;8(1):77-100.

19. Allport GW, Ross JM. Personal religious orientation and prejudice. J Pers Soc Psychol. 1967;5(4):432-43. [PubMed: 6051769].

20. Mokhtari A, Allahyari AA, RasolzadeTabatabai SK. The relationship of religious orientation with stress (in Persian). J Psychol. 2001;5(1):5667.

21. Dehghani M, Zoladl M, Boland-Parvaz S, Keshtkaran Z, Mahmoudi R, Jabbarnejad A. Asurvey on depression and its related factors in Nurses who work in Namazi Hospital of Shiraz University of Medical Sciences (in Persian). Iran Occupational Health. 2009;6(3):24-31.

22. Eliassen AH. Religious coping and depression in young adulthood: Effects of global stress exposure and pre-teenage religious service attendance. Review of Religious Res. 2013;55(3):413-33. doi: 10.1007/s13644013-0110-9.

23. Amrai K, AziziZalani H, Arfai FS, SadatSharifian M. The relationship between the religious oriention and anxiety and depression of students (in Persian). ProcediaSocBehav Sci. 2011;15:613-6.

24. Mansurnejad Z, Kajbaf MB. The relationship of religious orientation (intrinsic, extrinsic) and gender with death anxiety among students (in Persian). Res Cognitive Behav Sci. 2012;2(1):55-64.

25. Patti E, Acosta J, Chavda A, Verma D, Marker M, Anzisi L. Prevalence of anxiety and depression among emergency department staff. Nursing. 2007;48(2):8.

26. Dalmida SG, Koenig HG, Holstad MM, Wirani MM. The psychological well-being of people living with HIV/AIDS and the role of religious coping and social support. Int J Psychiatry Med. 2013;46(1):57-83. doi: 10.2190/PM.46.1.e. [PubMed: 24547610]. 